\title{
Экспертиза
}

МУСАТОВ Александр Александрович - главный специалист информационно-аналитического отдела Фонда информационного обеспечения науки (123557, Россия, г. Москва, ул. Пресненский Baл, 19, cmp.1; aamstv@yandex.ru)

МИРОНОВА Яна Сергеевна - специалист отдела научно-технического сопровождения экспертизы Фонда информационного обеспечения науки (123557, Россия, г. Москва, ул. Пресненский Baл, 19, cmp. 1; miryana1@yandex.ru)

\section{АНАЛИЗ КОМПЕТЕНЦИЙ И КВАЛИФИКАЦИИ НАУЧНЫХ СОТРУДНИКОВ - ЭКСПЕРТОВ В НАУЧНО-ТЕХНИЧЕСКОЙ СФЕРЕ}

\begin{abstract}
Аннотация. В статье анализируются результаты исследования компетенций и квалификационных характеристик научных сотрудников различных типов научных организаций, необходимых при приеме на научную должность по конкурсу на ее замещение. В данной статье используется понятие квалификационных характеристик научного сотрудника, а также рассматриваются минимальные квалификационные характеристики и компетенции (отраженные в конкурсной документации на замещение конкретной должности) различных категорий научных должностей в сравнении с независимыми экспертами, привлекаемыми к проведению экспертизы проектов в рамках реализации федеральной целевой программы «Исследования и разработки по приоритетным направлениям развития научно-технологического комплекса России на 2014-2020 годы»1. Авторы делают выводы относительно развития компетенций и существенного увеличения квалификационных характеристик в случае, если сотрудник выступает в качестве эксперта в области научно-технической сферы.
\end{abstract}

Ключевые слова: научно-техническая экспертиза, компетенция, квалификация, независимые эксперты, конкурс, федеральная целевая программа

тратегия научно-технического развития Российской Федерации ${ }^{2}$ выделяет роль российских исследователей в стратегическом планировании науки России, призывая создавать технические решения, повышающие конкурентоспособность отечественных компаний в борьбе за глобальные рынки [Зинов, Куракова, Черченко 2017: 24]. Государство обеспечило таким исследователям материальную поддержку: с 2018 г. повышение средней заработной платы преподавателей высшего профессионального образования и научных сотрудников должно составлять до $200 \%$ средней заработной платы по региону ${ }^{3}$. Таким образом, в наиболее развитом научном регионе - Москве - этот показатель в 2018 г. составил порядка 135 тыс. руб. в месяц.

В профессиональном научном сообществе не всегда различаются термины «квалификация» и «компетенции», поэтому ниже приведены определения, которые используются в настоящей статье.

Квалификация - готовность к выполнению определенного вида профессиональной деятельности, подтвержденная официальным документом в виде диплома, аттестата, сертификата, договора и т.п.

Компетенция - проявленная на практике способность и готовность индивида применять свои знания, умения и практический опыт для успешного решения

\footnotetext{
${ }^{1}$ Постановление Правительства РФ от 21.05 .2013 г. № 426 «О федеральной целевой программе "Исследования и разработки по приоритетным направлениям развития научно-технологического комплекса России на 2014-2020 годы”».

2 Указ Президента РФ от 1 декабря 2016 г. N 642 «О Стратегии научно-технологического развития Российской Федерации». Доступ: http://garant.ru/products/ipo/prime/doc/71451998

3 Указ Президента Российской Федерации от 07.05.2012 N 597 «О мероприятиях по реализации государственной социальной политики».
} 
поставленных перед ним задач, другими словами, - совокупность знаний, умений, опыта и личностных характеристик специалиста, необходимых для успешного выполнения его профессиональных задач.

Компетентность - способность специалиста решать профессиональные задачи, опираясь на свои знания, умения, опыт и личностные характеристики [Козодаев 2015: 281]. Перечень компетенций приводится в описании профессии (например, в Общероссийском классификаторе профессий ${ }^{1}$ ) или должности (в разделе «Требуемые компетенции» должностной инструкции).

Таким образом, квалификация - это готовность к выполнению определенного вида деятельности, подтвержденная документом, а компетенции (компетентность) - это готовность и способность, подтвержденная опытом, не требующие подтверждающих документов.

Оценка специалистов по модели компетенций (модель компетенций это структурированное и взаимоувязанное описание перечня важных для организации компетенций сотрудников [Козодаев 2015: 284]) и выстраивание всей системы оценки компетенций используется кадровой службой организации для оценки персонала, что предполагает всестороннее и длительное наблюдение за работой специалиста.

Эксперт в научно-технической сфере, как правило, занимается научной деятельностью, поэтому должен обладать, как минимум, всеми требуемыми компетенциями и квалификационными характеристиками научного сотрудника организации. Существует особенность в оценке компетенций экспертов. Работа эксперта (в частности, в области научно-технической экспертизы), а именно работа в удаленном режиме (получение документов, разъяснений, анализ результатов) и разовый характер работы, затрудняет всестороннее и длительное наблюдение заказчиком экспертизы за деятельностью эксперта и детальный анализ результатов его работы и, соответственно, оценку компетенций эксперта. Квалификации и компетенции экспертов являются основой для включения специалиста в реестр экспертов Программы. Поскольку основные компетенции и квалификация эксперта формируются еще на этапе его профессиональной деятельности, важным аспектом является информация о том, какими компетенциями и квалификационными характеристиками априори обладают кандидаты на научную должность (работники науки), которые в большинстве своем и являются экспертами, привлекаемыми для выполнения экспертизы научнотехнических проектов, и от компетентности которых как экспертов проектов зависит эффективность реализации этих проектов и выданного финансирования.

В данной статье будут проанализированы результаты исследования требований к компетенциям и квалификационным характеристикам кандидатов на научную должность, предъявляемых научными организациями различных организационно-правовых форм и форм собственности. Информация получена путем анализа конкурсной документации на замещение вакантной должности научного сотрудника разных категорий и ППС за 2010-2018 гг.

Для анализа были отобраны и проанализированы 60 научных организаций, в т.ч. Российская академия наук, высшие учебные заведения и научно-исследовательские институты (все научные организации, которые указали на своих сайтах информацию о конкурсах на замещение должности научного сотрудника).

При этом значительное число указанных выше организаций (16 организаций)

1 Общероссийский классификатор профессий рабочих, должностей служащих и тарифных разрядов ОК 016-94 (ОКПДТР). Принят постановлением Госстандарта РФ от 26.12.1994 N 367) (с изм. и доп.). Доступ: http://base.garant.ru/1548770/\#ixzz5DZmhnseD 
в принципе не предъявляли требования к научным сотрудникам, ссылаясь на требования, изложенные в следующих документах:

- постановление президиума $\mathrm{PAH}^{1}$, согласно которому кандидат на должность научного сотрудника обязан знать: цели и задачи проводимых исследований и разработок, отечественную и зарубежную информацию по теме исследования; современные методы организации исследований, обобщения и обработки полученной информации; современные методы наблюдений; средства проведения экспериментов и наблюдений; внутренние нормативные акты, приказы и распоряжения; правила и нормы охраны труда, пожарной безопасности;

- Единый квалификационный справочник должностей руководителей, специалистов и служащих ${ }^{2}$, также содержащий основные требования в отношении специальных знаний, предъявляемых к профессорско-преподавательскому составу, таких как знание законов и иных нормативных правовых актов РФ по вопросам высшего профессионального образования (ВПО); локальных нормативных актов образовательного учреждения; государственных образовательных стандартов по соответствующим программам ВПО; теории и методов управления образовательными системами; порядка составления учебных планов и Т.Д.

Сотрудники выбранных для исследования организаций были разделены на несколько групп в соответствии с занимаемой должностью:

- профессорско-преподавательский состав (далее - ППС) (профессор, доцент);

- научные сотрудники (главный научный сотрудник, ведущий научный сотрудник, старший научный сотрудник и научный сотрудник).

Анализ проводился по следующим минимальным требованиям конкурсной документации на замещение вакантной должности научных сотрудников и ППС: наличие публикаций (в изданиях, индексируемых в РИНЦ, Web of Science Core Collection и Scopus); наличие охраняемых прав на РИД; наличие научных трудов в совокупности (монографии, статьи в рецензируемых научных журналах, патенты); опыт (стаж) работы в научно-технической сфере на научных, инженерно-технических и/или руководящих должностях; ученая степень; участие в выполнении научных исследований за последние 3-5 лет.

Самые высокие требования по числу публикаций и научных трудов за последние 5 лет предъявляются к главному и ведущему научным сотрудникам (в среднем 5-8 публикаций), далее следуют профессор и старший научный сотрудник (4-6 публикаций) (см. рис. 1). Численные значения публикаций и научных трудов кандидатов на должности доцента и научного сотрудника практически идентичны и равны минимальным требованиям по данным показателям - от 2 до 4 публикаций.

По наличию охраняемых прав на РИД ситуация следующая: старший научный сотрудник и профессор в среднем должны иметь 1 патент в соответствующей его профилю научной области, ведущий и главный научные сотрудники - 2 и 3 патента соответственно.

Однако следует отметить, что на практике при проведении реальных кон-

1 Постановление Президиума РАН «Об утверждении Квалификационных характеристик по должностям научных работников научных учреждений, подведомственных Российской академии наук» № 196 от 25 марта 2008 г.

2 Приказ Министерства здравоохранения и социального развития Российской Федерации (Минздравсоцразвития России) от 11.01.2011 N 1н г. Москва «Об утверждении Единого квалификационного справочника должностей руководителей, специалистов и служащих, раздел “Квалификационные характеристики должностей руководителей и специалистов высшего профессионального и дополнительного профессионального образования”». 


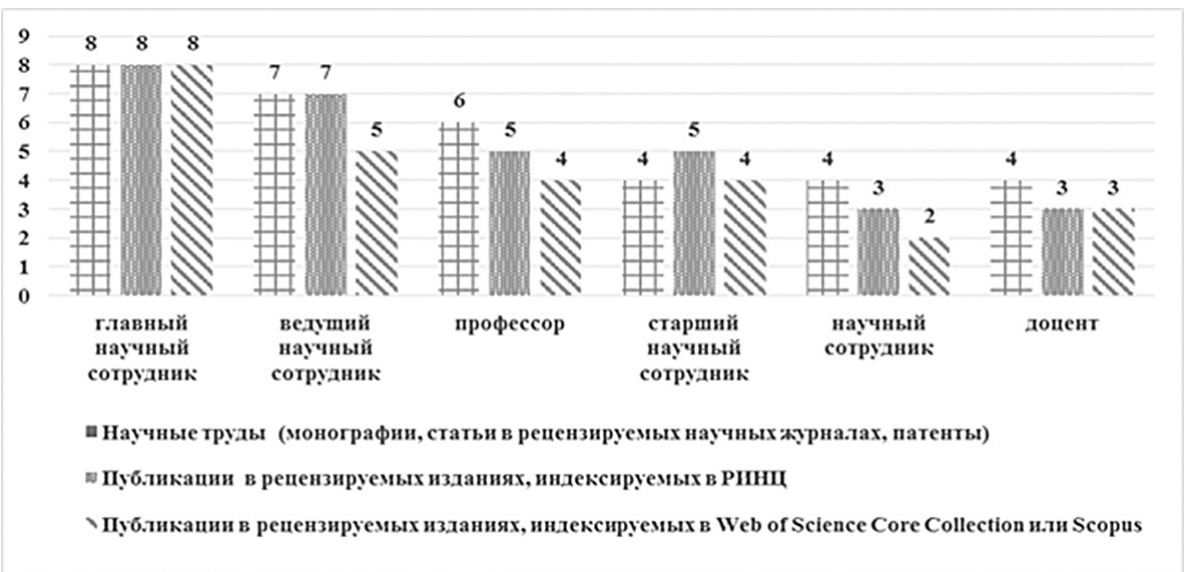

Рисунок 1. Требования к кандидатам на научную должность за последние 5 лет

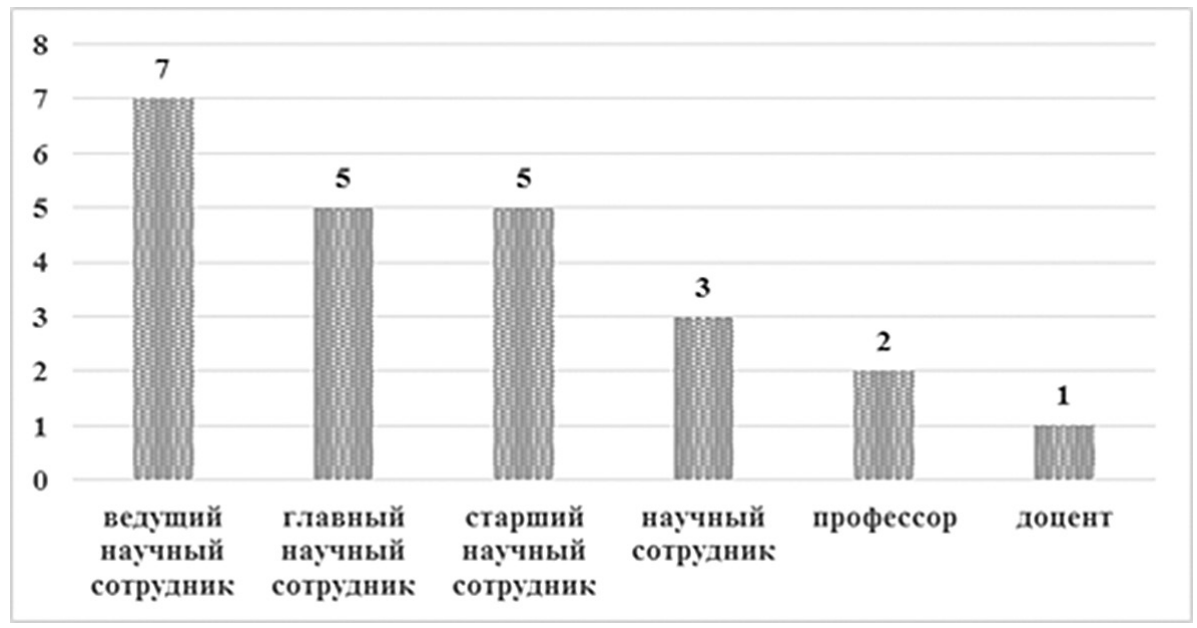

Рисунок 2. Требования к кандидатам на научную должность (наличие монографий)

курсов на замещение вакантной должности сотрудника эти условия не всегда выполняются, и некоторые показатели могут быть взаимозаменяемыми. В таком случае в требованиях к квалификации приводится следующая формулировка: «Наличие публикаций/монографий/патентов». Поэтому отсутствие РИД у потенциального сотрудника может быть компенсировано, например, наличием большего числа публикаций в журналах с высоким импакт-фактором или же монографии.

Относительно опыта работы в научно-технической сфере и участия в выполнении научно-технической деятельности отмечено следующее: требуемый стаж работы на научных, инженерно-технических и/или руководящих должностях для научного сотрудника и доцента составляет 3 года, для остальных исследуемых должностей - 5 лет.

В зависимости от типа организации научные сотрудники (ведущий, главный, старший) должны иметь: 
- опыт руководства работами (исследованиями) по грантам РФФИ, РГНФ, программам фундаментальных исследований РАН и ее отделений, федеральным программам и программам Минобрнауки России, российским и международным контрактам (договорам, соглашениям);

- реализованные на практике крупные проекты и разработки.

Участие в научной экспертизе проектов исследований и наличие результатов законченных исследований и разработок как специфическое требование было предъявлено к должности главного научного сотрудника всего лишь 2 организациями.

Для всех анализируемых групп работников обязательным является наличие высшего профессионального образования, а также ученой степени кандидата и/или доктора наук.

Кроме основных характеристик, одним из важных показателей квалификации кандидата на научную должность организации считают наличие монографий за весь период научной деятельности, средние значения которого представлены на рис. 2.

Среди других дополнительных требований, представленных в конкурсной документации на замещение вакантной должности научных сотрудников, наиболее часто предъявлялось требование об участии в общероссийских и зарубежных научных съездах, конференциях, симпозиумах и др. в качестве докладчика, а также опыт подготовки докторов и кандидатов наук, руководства аспирантами, соискателями, бакалаврами и магистрантами вузов.

В отличие от требований к квалификационным характеристикам, которые в той или иной степени были предъявлены всеми анализируемыми организациями, требования к компетенциям научных сотрудников и ППС со ссылкой на Единый квалификационный справочник представили лишь 14 организаций из 60 (что составило менее 25\%). Согласно данным требованиям, научные сотрудники всех категорий должны знать:

- законы и иные нормативные правовые акты Российской Федерации, методические и нормативные документы, касающиеся деятельности организации;

- научные проблемы в соответствующей области знаний, науки и техники, направления развития отрасли, руководящие материалы вышестоящих и других органов, отечественные и зарубежные достижения по исследуемым вопросам;

- новейшие методы, средства и практику планирования, организации, проведения и внедрения научных исследований и разработок (оценка, патентно-информационное обеспечение, выпуск научно-технической документации и т.п.);

- правила и нормы охраны труда, техники безопасности, противопожарной защиты.

В заключение сравним количественные показатели квалификационных требований, предъявляемых к кандидатам на научную должность, со средними значениями по тем же показателям, которыми обладают эксперты Программы.

Реестр экспертов Программы состоит: из научных сотрудников $-22,6 \%$, ППС - 15,8\%, управляющего персонала высшего звена (директор, заместитель директора, ректор и т.п.) - 14,4\%, управляющего персонала (заместитель начальника отдела, заведующий лабораторией и т.п.) - 29,17\%, инженерно-технических работников $-1,6 \%$, персонала (менеджер, ассистент и т.п.) $-1,15 \%$, без указания должности $-15,3 \%$.

Квалификационные характеристики экспертов Программы существенно выше требований к квалификации, представленных в конкурсной документации на замещение вакантной должности научных сотрудников и ППС (см. рис. 3). 


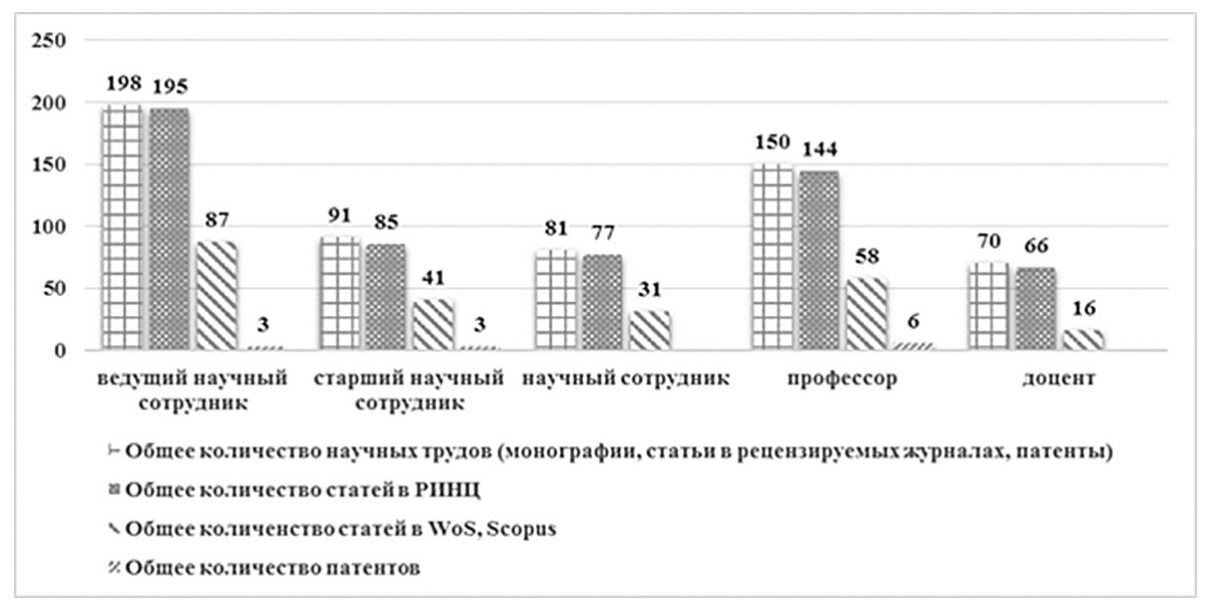

Рисунок 3. Квалификационные характеристики экспертов Программы

Анализ компетенций и квалификационных характеристик научных сотрудников, безусловно, является полезным и нужным инструментом для развития научно-технической экспертизы проектов, поскольку при помощи него происходит более тщательный подбор специалистов-экспертов с учетом их предрасположенности (возможности) к проведению экспертизы объекта в том или ином направлении и области науки. Первоначально отбор специалистов для включения в реестр экспертов происходит по минимальным компетенциям и квалификационным характеристикам, которые подробно описаны в настоящей статье и которые развиваются с течением времени. Причем такие зоны развития могут определяться как для исправления текущих недостатков в работе эксперта, так и для выявления специалистов, способных стать центром компетенций по каким-то вопросам оценки. Однако если подбор экспертов сводится только лишь к подобному анализу, то для научной сферы это может послужить не двигателем прогресса, а совсем наоборот, т.к. чрезмерное использование данного инструмента может лишь усложнить процесс подбора специалистов, превратив его в жесткую бюрократическую процедуру, что может сказаться, в конечном счете, на качестве экспертного заключения. Поэтому следует помнить, что всему есть разумные пределы. А для развития науки прежде всего нужна свобода!

\section{Список литературы}

Зинов В.Г., Куракова Н.Г., Черченко О.В. 2017. Анализ причин и последствий передачи полученных в России результатов интеллектуальной деятельности зарубежным компаниям. - Инновации. № 10. С. 24-30.

Козодаев М.А. 2015. Оценка проектного персонала: не забыть бы, для чего это делается (часть 1). - Управление проектами и программами. № 4. С. 280-297. 
MUSATOV Aleksandr Aleksandrovich, Chief Specialist of Information and Analytical Department, Foundation for Information Support of Science (bld. 1, 19 Presnensky Val St, Moscow, Russia, 123557; aamstv@yandex.ru)

MIRONOVA Yana Sergeevna, Specialist of the Department of Scientific and Technical Examination, Foundation for Information Support of Science (bld. 1, 19 Presnensky Val St, Moscow, Russia, 123557; miryana 1@yandex.ru)

\title{
ANALYSIS OF THE COMPETENCIES AND QUALIFICATIONS OF SCIENTIFIC EXPERTS IN THE SCIENTIFIC AND TECHNICAL SPHERE
}

Abstract. The article analyzes the results of the study of competences and qualification characteristics of researchers of various types of scientific organizations, necessary for admission to a scientific position. The authors use the concept of qualification characteristics of a researcher - readiness to perform a certain type of activity, confirmed by the document, and his competence (competency). The minimal qualification characteristics and competences of various categories of scientific positions in comparison with the independent experts involved in carrying out examination of projects within implementation of the Federal target program «Researches and developments in priority directions of the development of a scientific and technological complex of Russia for 2014-2020" are considered. Conclusions are made on the development of competencies and a significant increase in qualification characteristics of the employee acting as an expert in the field of scientific and technical sphere.

Keywords: scientific and technical expertise, expertise, skill, independent experts, competition, federal target program

\author{
УДК 94 (571.54)
}

БАЙКАЛОВ Николай Сергеевич - кандидат исторических наук, доцент кафедры истории Бурятии Бурятского государственного университета (670000, г. Улан-Удэ, ул. Ранжурова, 6, ayd. 2116; baikalov@bsu.ru)

\section{ПЕРЕСЕЛЕНИЕ ИЗ ВЕТХОГО И АВАРИЙНОГО ЖИЛЬЯ В РАЙОНАХ БАМА: ПРИЧИНЫ, ПРОБЛЕМЫ, РЕШЕНИЯ}

\begin{abstract}
Аннотация. Ветхое и аварийное жилье, возникшее в ходе сооружения БАМа в 1970-е-1980-е гг., составляет значительную долю жилищного фонда современных поселений, прилегающих к магистрали районов. Сегодня оно подлежит сносу по ряду причин, среди которых выделяются физический износ, нерентабельность содержания и ремонта, нарушение норм пожарной и санитарной безопасности, архитектурного облика поселений. Реализация мероприятий по ликвидации такого жилья и переселению жильцов началась на БАМе с конца 2010-х гг. В соответствии с действующим законодательством были разработаны региональные и муниципальные программы по расселению местных жителей. В работе рассмотрены особенности реализации данных программ, описаны источники и объемы финансирования, проанализированы способы достижения программных индикаторов, включая неформальные практики. Ключевые слова: районы БАМа, ветхое и аварийное жилье, региональные и муниципальные программы переселения, жилищные субсидии, малоэтажное строительство
\end{abstract}

$\mathrm{B}$ етхое и аварийное жилье является обязательным спутником всех современных поселений, история возникновения которых тесно связана с социалистической модернизацией, особенно в ее позднесоветском варианте. Сегодня в районах прохождения Байкало-Амурской магистрали насчитывается 1,2 млн кв. м ветхого жилья, на переселение из которого потребуется не 